\title{
Evaluating Critical Care Point of Care Testing (POCT) devices and tests in Nigeria
}

\author{
J Bolodeoku*1, S Bains ${ }^{1}, 0$ M Adegoke ${ }^{2}$, 0 F Ajani ${ }^{3}$, A D Olukuewu ${ }^{4}$ and 0 Ogbeiwi ${ }^{5}$ \\ ${ }^{1} J B$ Consulting MDP Ltd, United Kingdom \\ ${ }^{2}$ Olabisi Onabanjo University Teaching Hospital, Nigeria \\ ${ }^{3}$ Texilla American University, South America \& Body Affairs Diagnostics, Abuja
}

${ }^{4}$ Department of Haematology and Transfusion, Nigeria

${ }^{5}$ Department of Factfinders Consultancy Services Limited, England

*Corresponding author: J Bolodeoku, JB Consulting MDP Ltd, Cherwell Innovation Centre, 77 Heyford Park, Upper Heyford,

Oxfordshire, United Kingdom

\section{ARTICLE INFO}

Received: 䌜 December 19, 2019

Published: 蔧January 08, 2020

Citation: J Bolodeoku, S Bains, 0 M Adegoke, O F Ajani, A D Olukuewu, 0 Ogbeiwi. Evaluating Critical Care Point of Care Testing (POCT) devices and tests in Nigeria. Biomed J Sci \& Tech Res 24(3)2020. BJSTR. MS.ID.004052.

\begin{abstract}
A survey was carried out on healthcare professionals in Nigeria on point of care testing in critical care. The respondents considered the glucose test as the most essential critical test followed by Full Blood Count (FBC), and then electrolytes, urea and creatinine. Blood gases ranked quite low with only $62 \%$ of the healthcare professionals considering them as a critical blood test. This was confirmed as it was found that only $31.6 \%$ of the respondents had blood gases devices in their institutions. Abbott's i-STAT was the most common POCT device used for blood gas estimation by $45 \%$ of the respondents, followed by Instrumentation Laboratories, 3500 and 4000 series (9.8\%) and then by Roche's Cobas B221 (9\%). From the features of blood gas devices which included price of analyser, price of cartridge, analysis time, portability, range of tests, power supply and volume of blood used, the price of analyser, was the product feature that respondents considered as most important. About one third of respondents ranked analysis time or range of tests possible as a priority specification, while about one quarter prioritised portability, price of cartridge or volume of blood needed. Power supply was the lowest ranking feature.
\end{abstract}

\section{Introduction}

Critical care is still in its infancy in many low-income countries such as Nigeria [1]. These services have been affected by low wages, exodus of manpower, government inability to fund hospitals and corruption [2]. Fatality rates are quite high in Nigeria, Intensive care units' mortality rates have been described as $69.4 \%$ in severe head injury patients, $43.5 \%$ in medical neurological, 33\% and $52 \%$ in obstetric patients [2-6]. Laboratory tests and diagnostic equipment play critical roles in the management of severely ill patients. Laboratory tests are crucial in the management of patients in critical care situations and clinicians rely on the laboratory to provide them with the requested test in a timely fashion; the faster the results arrive to the clinician, the earlier they are able to initiate management. For example, acute respiratory infections are relatively common as the cause of death in children in developing countries [7] and therefore estimation of blood gases is of paramount importance. Since the introduction of portable analyzers, blood gas analysis has been an important diagnostic tool in assessing the critically ill patient.

Point-of-Care Testing (POCT) is the term given to the diagnostic testing performed usually by means of a portable device near the patient, outside the main laboratory setting [8]. The main advantage of POCT devices is the reduction of turnaround time. This eliminates some steps in the laboratory testing process, such as specimen transport and result distribution, as well as specialist sample taking and second party reading and recording of the result [9]. An earlier survey on POCT devices in Nigerian physicians showed that blood gases devices were owned or used by $10 \%$ to $40 \%$ of the doctors [10]. Furthermore, the laboratory turn-around times showed that in critical care departments such as emergency, dialysis and intensive care units, the average turn-around time 
was between 5.12 - 8.33 hours. Interestingly, $20 \%$ - 47\% of the clinicians received their results less than 2 hours after a request for acute situations in the emergency, special care, intensive care and dialysis units [11]. It was concluded that laboratory turnaround times in the critical situation in Nigeria could be improved with the use of point of care blood gas testing devices. Based on this we decided to conduct another survey to fully understand critical care laboratory tests and use of POCT blood gas analyzers in Nigeria from a population consisting of mainly laboratory scientists, technicians and a few clinicians.

\section{Materials and Methods}

\section{Part 1}

A survey was carried out on a total of 95 laboratory scientists, laboratory technicians, doctors and nurses in Nigeria, to get an understanding into their knowledge of laboratory tests requested in a critical situation and the use of POCT devices. The respondents were asked to answer closed-ended questions of a structured questionnaire with fixed multi-answer options on SurveyMonkey. A random sampling method was used for collecting the primary data for the study. The population was taken from a database, which consisted of $65 \%$ laboratory scientists/technicians, 19\% doctors and $16 \%$ nurses. $67 \%$ of the respondents were based in public health institutions and the remaining 33\% from Private health institutions (Figure 1). The questionnaire was mailed out to the respondents and completed and returned, the respondents were compensated with $£ 10$ worth of airtime on their mobile phones for taking part in the study.

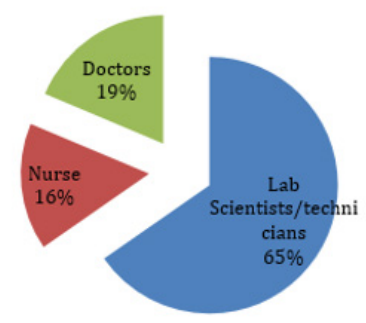

Figure 1: Population of respondents.

The questions asked in the questionnaire were as follows:

1. Which critical care tests do you believe are essential for your practice?

2. How many tests are carried out in your establishment a month?

3. Tick the box for the point of care device you have in your establishment.

4. Which of these devices do you know of that are used to measure blood gases in your establishment? Which of these devices have you used to perform blood gas estimations on?
5. What do you look for in the specifications of a point of care blood gas analyser? Please rank in order from 1st - 7th, left to right.

\section{Results}

Question: Which critical care tests do you believe are essential for your practice?

The survey assessed which of the 10 tests were seen as essential. In their order of popularity, as per the response percent of the total 95 respondents, the glucose blood test was considered the most essential critical test followed by full blood count (FBC), electrolytes, blood gases, cardiac and clotting markers. Blood gases ranked quite low with only $62 \%$ of the healthcare professionals considering them as essential in critical care management. Cardiac and clotting markers ranked the lowest at 56\% and 54\%, respectively (Figure 2).

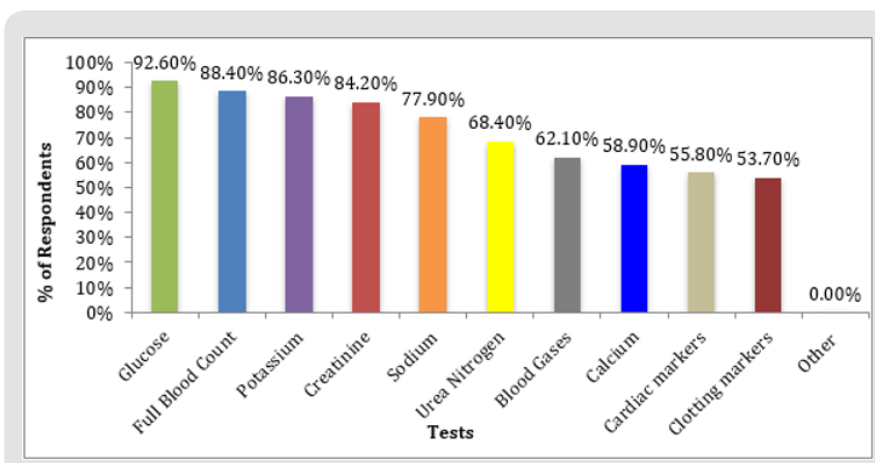

Figure 2: Tests considered essential.

Question: How many tests are carried out in your establishment a month?

Table 1: Number of critical care tests performed per month.

\begin{tabular}{|c|c|c|}
\hline \multirow{2}{*}{ Test } & \multicolumn{2}{|c|}{ Total } \\
\hline & Response Average & Response Count \\
\hline 1. Full Blood Count & 1108.6 & 93 \\
\hline 2. Glucose & 753.6 & 94 \\
\hline 3. Creatinine & 661.9 & 91 \\
\hline 4. Potassium & 631.2 & 92 \\
\hline 5. Sodium & 628.3 & 90 \\
\hline 6. Urea Nitrogen & 618.4 & 89 \\
\hline 7. Calcium & 384.3 & 84 \\
\hline 8. Blood Gases & 164.1 & 74 \\
\hline 9. Clotting markers & 146.5 & 74 \\
\hline 10. Cardiac markers & 90.5 & 64 \\
\hline $\mathrm{N}=$ & 95 & \\
\hline
\end{tabular}

Table 1 showed the monthly average number of critical care tests done in the respondents' institutions. The total monthly tests performed on average ranged from 90.5 tests for cardiac markers to 1,108.6 tests for FBC. The glucose test was second to FBC in the average number of monthly tests of 753.6, and ahead of the group of electrolytes tests. There was a comparatively lower number 
of tests performed monthly for blood gases, cardiac and clotting markers (Table 1).

Question: Tick the box for the point of care device you have in your establishment?

The commonest POCT device was shown to be blood glucose meters, present in the establishments of $91 \%$ of the respondents
(Figure 3). The answers were split in 3 groups: The first group of POCT devices (glucose, pregnancy, urine chemistry, electrolytes, coagulation and bilirubin) were owned or used by more than $40 \%$ of the respondents, the second group of POCT devices (cholesterol, blood gases, cardiac enzymes and drugs of abuse) were owned or used by $10 \%$ to $40 \%$ of the respondents.

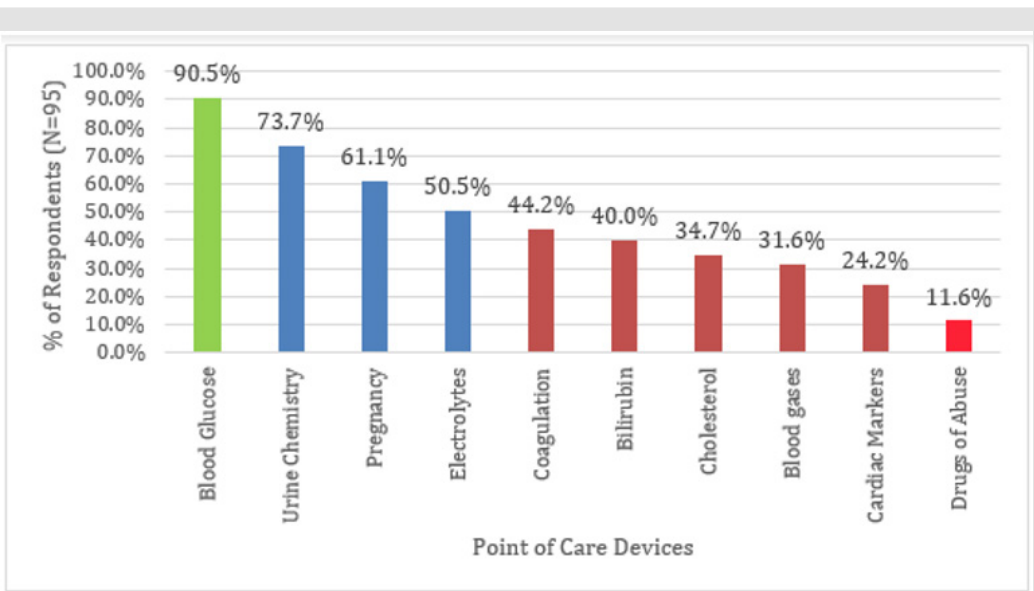

Figure 3: Graph showing possession of Point of Care Devices in Respondents' Establishments.

Question: Do you know which of these devices are used to measure blood gases in your establishment? \& which of these devices have you used to perform blood gas estimations on?

The respondents were provided a list of 14 blood gas devices:

1. Abbott i-STAT

2. Roche Cobas b 221

3. Instrumentation Laboratory GEM Premier 3500

4. Instrumentation Laboratory GEM Premier 4000

5. Nova Biomedical Critical Care Xpress
6. Siemens RAPIDPoint $340 / 350$

7. Radiometer ABL 80

8. $\quad$ Opti Medical OPTI CCA-TS

9. Radiometer ABL 800

10. Siemens RAPIDLab 1200

11. Siemens RAPIDPoint $400 / 405$

12. ITC IRMA TruPoint,

13. Opti Medical OPTI R

14. Nova Biomedical pHOx series

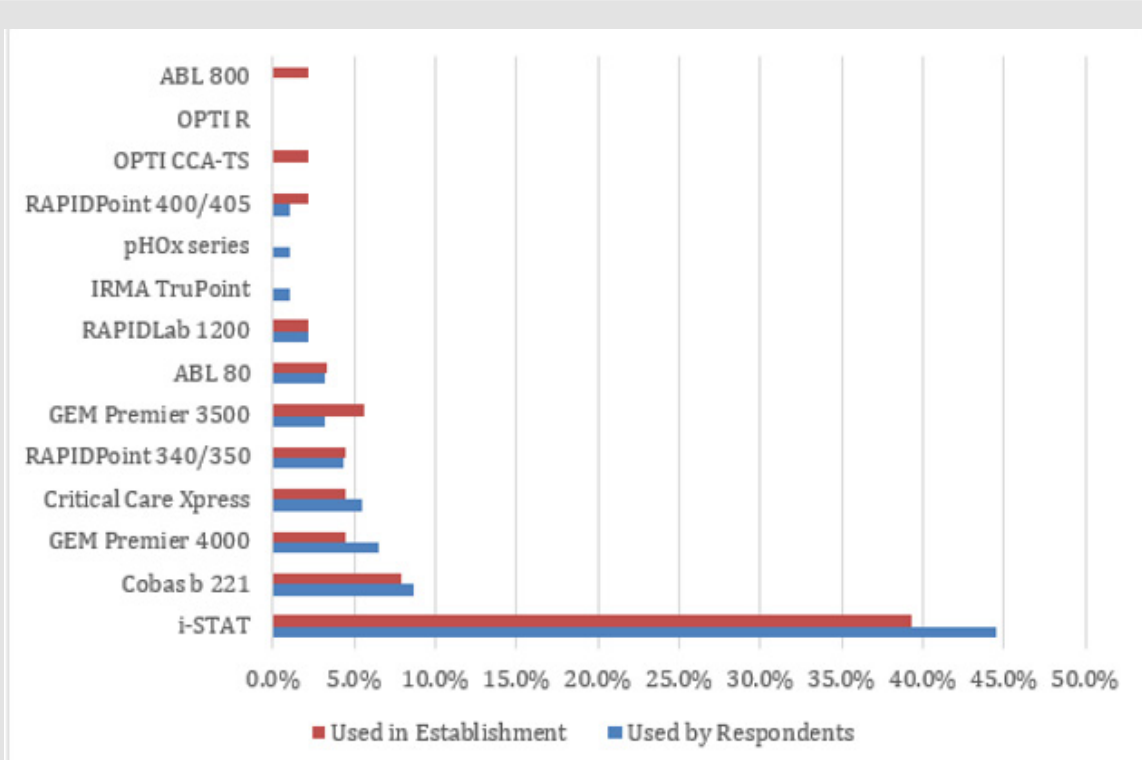

Figure 4: Graph to show the frequency of use of several brands of Blood Gases Devices. 
The devices used by respondents had comparable percentages to those used in their establishments. The Abbott i-STAT stood out as the main analyser used by $45 \%$ of the respondents, followed by the Cobas b221, GEM Premier 400 and Critical care Express by 5 $10 \%$ of the respondents (Figure 4).

Question: Ranking of product features for blood gas devices.

Ranking of the specifications for Blood Gases Devices. The respondents were provided with a choice of 7 product features of blood gas devices:

1. Price of analyser

2. Analysis time
3. Price of test cartridge
4. Portability
5. Range of tests
6. Volume of blood required
7. Power supply

The price of analyser device is ranked first and the power supply is $7^{\text {th }}$. There may be no significant statistical differences in the prioritisation of analysis time, price of cartridge, portability and range of tests ranked $2^{\text {nd }}, 3^{\text {rd }}, 4^{\text {th }}$ and $5^{\text {th }}$ respectively (Figure 5).

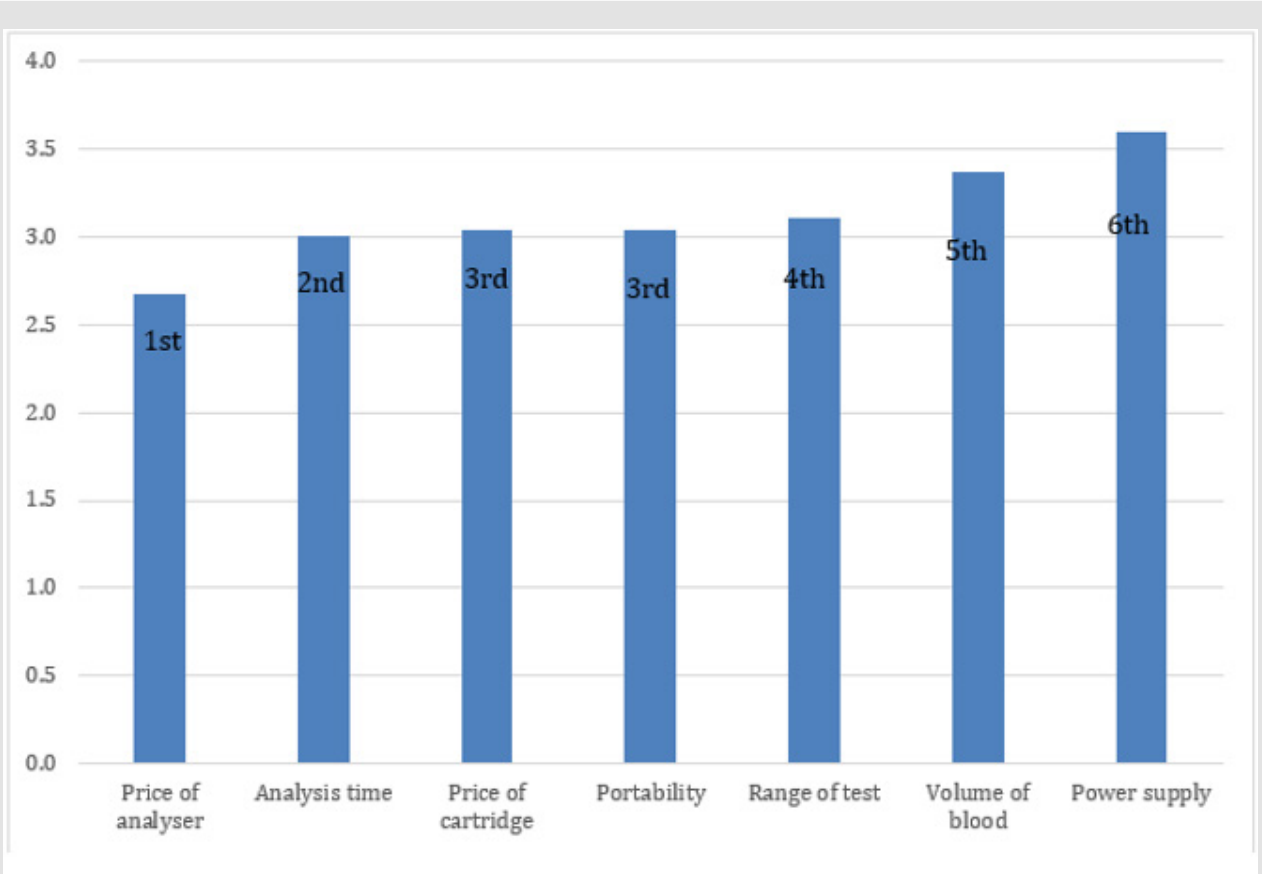

Figure 5: Graph to show Respondents' Ranking of Specifications for Blood Gas Devices.

\section{Discussion}

Performing laboratory tests is important in assessing the critically ill patient, tests such as blood gases, glucose, sodium, potassium, ionized calcium, haematocrit/haemoglobin have been identified as critical laboratory test in air ambulances [12]. In this study, the respondents considered the glucose test as the most essential critical test followed by Full Blood Count (FBC), electrolytes, urea and creatinine (68\% - 86\%). This is comparable to an earlier survey carried out on physicians, where the top three analytes selected to be available at point of care were glucose, potassium and haemoglobin [10]. Tests for blood gases, cardiac markers and clotting were not considered as highly as the others as critical laboratory tests, this observation is confirmed based on the number of tests performed monthly by their respective laboratories. The average number of blood gas tests amounts to a quarter of the average number of basic electrolytes tests. This observation may be a reflection of the lack of ability to perform these tests for these parameters by the individuals in their institutions locally or externally. POCT plays a paramount role in managing the patients in critical care situations like the operating room, emergency room, and intensive care unit $[13,14]$.

In an earlier study in Nigerian physicians, only about a third (32.1\%) had access to a POCT device that measures electrolytes. Less than that number had access to a POCT device that measures blood gases (16.5\%), coagulation $(21.1 \%)$ and cardiac enzymes (5.5\%) [10]. In this study, a higher number of respondents had a POCT device in their institutions for electrolytes (50.5\%), blood gases (31.6\%), coagulation (44.2\%) and cardiac markers $(24.2 \%)$, the reason for this is most likely due to the composition of the respondents which are more predominantly laboratory personnel. There are several POCT devices that are used in critical care such as Abbott i-STAT, Roche Cobas b 221, GEM Premier 3500, 4000, Nova Biomedical Critical Care Xpress, Siemens RAPIDPoint 340/350, RAPIDPoint 400/405, RAPIDLab 1200, Radiometer ABL 80, Opti 
Medical OPTI CCA-TS, Radiometer ABL 800, ITC IRMA TruPoint, Opti Medical OPTI R and Nova Biomedical pHOx series. In this study, the Abbott i-STAT stood out as the main analyser used by $45 \%$ of the respondents, followed by the Cobas b221, GEM Premier 400 and Critical Care Express by $5-10 \%$ of the respondents.

These results are comparable to findings in an earlier survey conducted solely on a small number of physicians, the Abbott i-STAT device was the most commonly owned or used from the POCT devices list that was provided which consisted of Abbott's-iSTAT, Roche-AVL Opti, Bayer-Rapid Point 400, Bayer-Chiron, Nova Biomedical-Nova, Radiometer-ABL, ABL 70/77, Instrumentation Laboratory-GEM Premier, Synthesis, Diametrics-ITC IRMA [10]. In a survey on the market share of hospitals using a blood gas POCT device in the United States of America carried out by Enterprise Analysis Corporation, fifty four percent (54\%) had the Abbott i-STAT device, with 14\% using the IL GEM Premier instruments and $8 \%$ using the Radiometer ABL [15]. It appears that the i-STAT device is the market leader even in developing countries like Nigeria. In the acquisition of POCT devices, it is important to appreciate the features of the product that would interest clinicians and laboratory personnel. From the features of blood gas devices provided which included price of analyser, price of cartridge, analysis time, portability, range of tests, power supply and volume of blood used. In this study, not surprisingly the price of analyzer, was the product feature that respondents considered as most important.

About one third of respondents ranked analysis time or range of tests possible as a priority specification, while about one quarter prioritized portability, price of cartridge or volume of blood needed. Power supply was the lowest ranking feature, this was quite surprising considering that the country is subject to a large number of electricity power cuts. In this survey where the respondents were predominantly laboratory personnel in Nigeria, respondents considered the glucose test as the most essential critical test followed by full blood count (FBC), and then electrolytes, urea and creatinine (68\%-86\%). Blood gases ranked quite low with only $62 \%$ of healthcare professionals considering them as a critical blood test. This was confirmed by $31.6 \%$ of respondents having blood gases devices in their institutions. Abbott's, I-STAT was the most common POCT device used for blood gas estimation, followed by Instrumentation Laboratories, 3500 and 4000 series (9.8\%) and then Roche's Cobas B221 (9\%). The price of analyser was the product feature that respondents considered as most important
In conclusion, the findings from this study on critical care testing show that measuring blood gases, cardiac and coagulation markers are still in its infancy in developing countries like Nigeria and price may play an important factor in the acquisition of the POCT devices.

\section{References}

1. Amoateng Adjepong Y (2006) Caring for the critically ill in developing countries-our collective challenge. Crit Care Med 34(4): 1288-1289.

2. Okafor UV, Aniebue U (2004) Admission pattern and outcome in critical care obstetric patients. Int J Obstet Anaesth 13(3): 164-166.

3. Osinaike BB, Amanor Boadu SD, Sanusi AA (2006) Obstetric intensive care: A developing country experience. Int J Anaesthesiol 16: 2.

4. Ohaegbulam SC, Okafor UV, Ihekire O, Elemelu V (2007) Using the revised trauma score to predict outcome in severely head injured patients in a developing country: A pilot study. J Coll Med 12: 51-55.

5. Okafor UV, Onwuekwe I (2004) Disease pattern and outcome for medical neurological patients admitted to a multi-disciplinary Intensive Care Unit. J Coll Med 9: 113-115.

6. Okafor UV (2009) Challenges in critical care services in Sub-Saharan Africa: Perspectives from Nigeria. Ind J Crit Care Med 13: 25-27.

7. Perrelet A, Zellweger JP, Talla I, Ndiaye Y, Gautier E, et al. (2004) The oxygen concentrator, an appropriate technology for treating hypoxaemic children in developing countries. The Int J of Tuberculosis and Lung Disease 8(9): 1138-1141.

8. Kost GJ (2002) Goals, guidelines and principles for point of care testing. In: Kost GJ edn, Principles and Practices of Point of Care Testing. Philadelphia: Lippincott Williams and Wilkins 2002

9. Plebani M (2009) Does POCT reduce the risk of error in laboratory testing? Clin Chim Acta 404(1): 59-64.

10. Bolodeoku J, Kuti MA, Melichan B, Adebisi SA (2016) A Survey Of The Awareness, Knowledge, And Experience Of Point-Of-Care Devices of Doctors In Nigeria. Point of Care: The Journal of Near-Patient Testing \& Technology 15(1): 22-25.

11. Bolodeoku J, Ogbeiwi O, Kuti MA, Adebisi SA (2017) Laboratory tests turnaround time in outpatient and emergency patients in Nigeria: results of a physician survey on point of care testing. IJMRHS 6(5): 7681.

12. Di Serio F, Petronelli MA, Sammartino E (2010) Laboratory testing during critical care transport; point of care testing in air ambulances. Clin Chem Lab Med 48(7): 955-961.

13. Lamb LS, Parrish RS, Goran SF, Biel MH (1995) Current nursing practice of point of care laboratory diagnostic testing in critical care units. Am J Crit Care 4: 429-433.

14. Herr DM, Newton NC, Santrach PJ, Hankins DG, Burritt MF, et al. (1995) Airborne and rescue point-of-care testing. Am J Clin Pathol 104(4): S54-S58.

15. Hughes M (2002) Market Trends in Point of Care Testing. Point of Care: The Journal of Near-Patient Testing \& Technology 1(2): 84-94. 
ISSN: 2574-1241

DOI: 10.26717/BJSTR.2020.24.004052

J Bolodeoku. Biomed J Sci \& Tech Res

\section{(c) (P) This work is licensed under Creative}

Submission Link: https://biomedres.us/submit-manuscript.php

$\begin{array}{ll}\text { BIOMEDICAL } & \text { Assets of Publishing with us } \\ \text { RESEARCHES } & \text { Global archiving of articles } \\ & \text { - Immediate, unrestricted online access } \\ & \text { - Rigorous Peer Review Process } \\ \end{array}$

